\title{
Estradiol Increases Female Sexual Initiation Independent of Male Responsiveness in Rhesus Monkeys
}

\author{
J ulia L. Zehr, ${ }^{1}$ Dario Maestripieri, and Kim Wallen \\ Department of Psychology and Yerkes Regional Primate Research Center, \\ Emory University, Atlanta, Georgia 30322
}

Received December 8, 1997; revised December 19, 1997; accepted January 20, 1998

\begin{abstract}
Copulation and female initiation of sexual behavior vary across the ovarian cycle, suggesting that female hormonal condition influences female sexual motivation in rhesus monkeys. However, the effects of hormones on female sexual motivation are difficult to identify because male behavior also varies with female hormonal condition. During the nonbreeding season, male rhesus monkeys are sexually unresponsive to females; thus the effects of estradiol treatment on female sexual motivation can be examined independent of male behavior. This study administered estradiol to five ovariectomized females living in a large age-graded social group during the nonbreeding season. The behavior of these females with and without estradiol treatment was compared. Data were collected concurrently on five intact, noncycling, nonpregnant females. Estradiol treatment significantly increased sexual initiation by ovariectomized females toward males without any signific ant changes in male behavior. Estradiol-treated females also displayed greater sexual initiation than nonpregnant, intact females. Both estrogen and progesterone were important predictors of sexual initiation in females, with progesterone having an inhibitory effect. Endogenous progesterone levels in females were negatively correlated with male contact behavior, suggesting that female attractiveness is reduced by progesterone. This study provides further support for estrogen as the critical steroid increasing female sexual motivation in primates. $\odot 1998$ Academic Press
\end{abstract}

Mating behavior in rhesus monkeys under a variety of social conditions varies with the female's hormonal state and increases near the time of ovulation (Goy, 1979; Wallen, 1990). It has been suggested that this cyclical variation in sexual behavior reflects ovarian modulation of female sexual motivation (Wallen, 1990,

\footnotetext{
${ }^{1}$ To whom correspondence should be addressed.
}

1995); studies of group-living animals support this view (Gordon, 1981; Wallen and Winston, 1984; Wallen, Winston, Gaventa, Davis-DaSilva, and Collins, 1984). However interpretation of these studies is difficult, because both male and female behaviors vary with the ovarian cycle. Thus, males could be responding to some aspect of female attractiveness such as cyclical changes in sex skin coloration (Czaja, Robinson, Eisele, Scheffler, and Goy, 1977) or a cyclically changing olfactory cue (Goldfoot, 1981). The situation is even less clear in studies of caged male-female pairs; in these studies, female sexual behavior is reported not to vary reliably with her hormonal condition (Michael and Bonsall, 1979). However, by increasing the female's ability to control mating with a male, some studies of rhesus monkey pairs have provided evidence of hormonal changes affecting female sexual motivation. For example, when the male's mobility is limited by tethering, female proceptive behaviors are higher in the follicular phase than in the luteal phase (Pomerantz and Goy, 1983). Similarly, if the male is placed behind a wire partition, the female spends more time near the partition at midcycle than she does at other cycle phases (Czaja and Bielert, 1975). Finally, when a female must perform an operant task to gain access to a male, females perform the task faster when estrogen levels are high (Bonsall, Zumpe, and Michael, 1978). Thus, when male and female contributions to the sexual interaction are separately investigated in pair-tests, evidence of hormonal modulation of female sexual motivation is found. In contrast, in age-graded intact rhesus monkey groups, it has not been possible to observe changes in female sexual behavior without correlated changes in male behavior. Thus the relationship between ovarian hormones, female sexual motivation, and the occurrence of cyclical 
changes in sexual behavior in quasi-natural social groups remains unclear.

Rhesus monkeys are seasonal breeders whose period of maximum sexual activity varies with their geographic location (Van Horn, 1980). At the Yerkes Regional Primate Research Center, mating behavior by intact rhesus monkey females occurs almost exclusively between the months of September and February with few, if any, sexual interactions during the rest of the year (Gordon, Bernstein, and Rose, 1978; Herndon, Turner, Ruiz de Elvira, and Collins, 1987). The lack of sexual activity during the nonbreeding season is also associated with a cessation of reproductive function in both males and females (Gordon, Bernstein, and Rose, 1978; Walker, Wilson, and Gordon, 1984).

To investigate the possible role of estrogen in stimulating female sexual motivation in primates, we manipulated estradiol levels in ovariectomized rhesus females living in large, stable, social groups at a time in the nonbreeding season when sexual behavior among males and intact females had ceased. We used the female sexinitiating behaviors of proximity, contact, grooming, and presentations to indicate underlying changes in female sexual motivation. Concurrent data were collected on intact nonpregnant group females that were no longer showing ovarian cycles after the end of the breeding season. We report here evidence of changes in female sexual initiation that occur in the absence of similar changes in male sexual behavior.

\section{METHOD}

\section{Subjects and Housing}

Study subjects were 5 ovariectomized and 5 intact, nonpregnant rhesus macaque females living in a longestablished social group composed of 3 adult males, 46 adult females, and their immature offspring. The group was housed in a $30 \times 30 \mathrm{~m}$ outdoor compound with attached indoor enclosure at the Field Station of the Yerkes Regional Primate Research Center of Emory University in Lawrenceville, Georgia. Monkeys were fed twice daily and water was freely available. All intact females were multiparous and ranged in age from 6 to 15 years. All ovariectomized females underwent bilateral ovariectomy at 1 year of age and were 16 years old at the time of the study. All research was conducted according to the guidelines published in the NIH Guide for the Care and Use of Laboratory Animals and was approved by the Yerkes Institutional Animal Care and Use Committee.

\section{Procedures}

The study was conducted in 12 weeks during the rhesus birth season, from April to July 1997. As soon as the first three infants were born in the group, multiparous females were screened for pregnancy with ultrasonography. Six nonpregnant females were recruited as subjects. However, one female was not included in the study, because she showed cyclically elevated estrogen levels indicating continuing ovarian activity in the first weeks of the study.

The five ovariectomized females were treated with estradiol during either the first $6(N=2)$ or the second 6 weeks of the study $(N=3)$. Treatments used $4.5-\mathrm{cm}$ Silastic capsules which contained crystalline $17 \beta$-estradiol (Product E-8875, Sigma Corp.) and were implanted subcutaneously in the space between the scapulae on the subject's back.

On the same day and between 1000 and $1300 \mathrm{~h}$ each week, blood samples were obtained for each subject. Subjects were trained to go into an indoor area, where they were transferred via a transfer box into a cage modified with small openings in the front. This cage allowed the subject to present a leg for collection of the blood sample. One 3-ml blood sample was obtained from the saphenous vein without anesthesia by holding the subject's leg. The animals were well accustomed to this procedure, and handling time prior to collection of the blood sample was typically under 1 min for each animal. The animal was quickly released into the group after blood sampling. Blood samples were centrifuged and plasma was frozen at $-20^{\circ} \mathrm{C}$ until assayed for $17 \beta$-estradiol and progesterone.

Each week, all subjects were focally observed for $1 \mathrm{~h}$ from an observation tower which allows an unrestricted view of the outdoor compound. Data were collected with a portable computer programmed to allow the recording of frequencies, durations, and sequences of behavior in real time. Behavioral observations included a number of social and nonsocial behaviors. Data analysis focused on the interactions between the female subjects and the three adult males. The following measures were used in the analysis:

(1) Approach to proximity. An approach was defined as a reduction of distance between two individuals from more than $60 \mathrm{~cm}$ to less than $60 \mathrm{~cm}$ without making contact for at least $5 \mathrm{~s}$. The total number of approaches made by the females or by the males was calculated.

(2) Proximity duration. The total time spent in proximity $(<60 \mathrm{~cm})$ without making contact when 
proximity was initiated by either the female or the male was calculated.

(3) Contact. Contacts included any body contacts except brief touching or hitting. The total number of body contacts initiated by either the females or the males was calculated.

(4) Contact duration. Contact duration was defined as the time spent in contact when not grooming or in other social activities.

(5) Grooming bout. The total number of allogrooming bouts initiated by the females or the males was calculated.

(6) Grooming duration. The total time spent allogrooming when grooming was initiated by either the females or the males was determined.

(7) Present. The total number of hindquarters presentations (Altmann, 1962) made by the females toward the males was determined.

(8) Mount. The total number of mounts (Altmann, 1962) initiated by the males was calculated.

(9) Aggression. Aggression was measured as the total number of threats, slaps, bites, or chases (Altmann, 1962) initiated by either the females or the males.

\section{Hormonal Assays}

Hormones were assayed with radioimmunoassay using kits produced by Diagnostic Products Corp. (Los Angeles, CA). The estradiol assay had sensitivity of 5-7 $\mathrm{pg} / \mathrm{ml}$ with an intra-assay coefficient of variation (CV) of $6 \%$ and an interassay $\mathrm{CV}$ of $11 \%$. The progesterone assay had a sensitivity of $200 \mathrm{pg} / \mathrm{ml}$, with an intra-assay CV of $4 \%$ and an interassay CV of $10 \%$.

\section{Selection of Nonpregnant Female Data}

There were no statistically significant differences between the first 6 weeks and the second 6 weeks of the study in the nonpregnant females' behavior. Because treatment of the ovariectomized females was counterbalanced, we quasi-counterbalanced the nonpregnant female data. Nonpregnant females were randomly paired with the ovariectomized females to form "treatment" groups. Three nonpregnant females were selected to have their data compared to the three ovariectomized females who were untreated during the first 6 weeks. The other two nonpregnant females were paired with the other two ovariectomized females. Thus, when comparing nonpregnant females to ovariectomized females, data from the two groups were collected from the same time periods.

\section{Statistical Analysis}

Repeated-measures analysis of variance (ANOVA) was used to examine differences between ovariectomized females with and without estradiol treatment in both male- and female-initiated behaviors. For each behavior, the effects of treatment order were analyzed. For two behaviors (female-initiated contact duration and male-initiated contact) treatment order accounted for a significant amount of the variance. These behavioral measures were adjusted using a correction factor based on the means of the first and second treatment periods (Keppel, 1991) and repeated-measures ANOVAs were then performed on the values corrected for order. Treatment order did not account for a significant amount of the variance for all other behavioral or hormonal measures and was therefore not included in the analysis for those measures (Keppel, 1991).

Independent samples $t$ tests were used to test for differences between ovariectomized females and nonpregnant females for both female- and male-initiated behaviors. If Levene's test for equality of variances was significant, the degrees of freedom were recalculated so that equal variances were not assumed. Significance was then calculated using the corrected degrees of freedom (SPSS for Windows, 7.5.1, SPSS Inc.). Estradiol-treated and untreated ovariectomized females were compared with nonpregnant females according to the nonpregnant selection criteria described above.

Data from estradiol-treated ovariectomized females and nonpregnant females were used to analyze the relationship between hormone levels and behavior. Mean estradiol and progesterone levels were calculated for each individual and were entered into a stepwise regression analysis with the behavior as the dependent variable. The hormone with the higher degree of independent correlation was entered into the regression analysis first.

A criterion of $P \leq 0.05$ was chosen to be statistically significant. Analyses in which $P \leq 0.10$ are reported, though they are not considered significant. All averages are reported as the mean \pm standard error of the mean.

\section{RESULTS}

\section{Effects of Estradiol Treatment within Ovariectomized Females}

Estradiol implants increased estradiol levels to $252.3 \pm 38.2 \mathrm{pg} / \mathrm{ml}$ in ovariectomized females (Table $1)$. When untreated, these females all had levels of 
TABLE 1

Hormonal Levels in Estrogen-Treated and Untreated Ovariectomized Females and in Nonpregnant Females

\begin{tabular}{|c|c|c|c|c|c|c|}
\hline Hormone & $\begin{array}{c}\text { Ovex with E } \\
(\text { Mean } \pm \text { SEM) }\end{array}$ & $\begin{array}{l}\text { Ovex without } E \\
(\text { Mean } \pm \text { SEM) }\end{array}$ & $\begin{array}{c}\text { Nonpregnant } \\
\text { females } \\
\text { (Mean } \pm \text { SEM) }\end{array}$ & $\begin{array}{l}\text { Ovex E vs } \\
\text { Ovex No E } \\
F(1,4) ; P\end{array}$ & $\begin{array}{c}\text { Ovex E vs } \\
\text { Nonpregnant } \\
F(1,9) ; P\end{array}$ & $\begin{array}{c}\text { Ovex No E vs } \\
\text { Nonpregnant } \\
F(1,9) ; P\end{array}$ \\
\hline Estrogen & $252.3 \pm 38.2$ & $\begin{array}{l}<10 ; \text { below assay } \\
\text { resolution }\end{array}$ & $25.5 \pm 5.6$ & Not calculated & $34.5 ; 0.001$ & Not calculated \\
\hline Progesterone & $655 \pm 93$ & $630 \pm 113$ & $647 \pm 26$ & $\leq 1.0 ; \mathrm{ns}$ & $\leq 1.0 ; \mathrm{ns}$ & $3.1 ; \mathrm{ns}$ \\
\hline
\end{tabular}

Note. Hormone levels are reported in $\mathrm{pg} / \mathrm{ml}$.

estradiol that were below the level of assay detectability $(<10 \mathrm{pg} / \mathrm{ml}$; Table 1$)$. The estradiol implants did not affect progesterone levels in ovariectomized females. Estradiol-treated females had a mean circulating progesterone level of $660 \pm 90 \mathrm{pg} / \mathrm{ml}$ while untreated females had a mean progesterone level of $630 \pm 110 \mathrm{pg} / \mathrm{ml}$ (Table 1$)$.

Female-initiated interactions with males increased significantly during estradiol treatment (Table 2). Estradiol treatment significantly increased female-initiated approaches, contacts, grooming bouts, and presentations compared to those of untreated females (Fig. 1a). Females initiated more time in contact with males during estradiol treatment (Fig. 1b). Although estradiol-treated females spent more time in proximity and more time in grooming bouts with males than did untreated females, these differences were not statistically significant (Fig. 1b). Female-initiated aggression toward males was not observed in this study. In contrast to female-initiated interactions, male-initiated interactions with females were unaffected by the estradiol treatment of the females (Table 3). Males were not observed to ejaculate with females under either treatment condition.

\section{Comparisons between Nonpregnant Females and Ovariectomized Females}

Estradiol levels in nonpregnant females were significantly lower than those in estradiol-treated ovariectomized females (Table 1). Nonpregnant females had mean estradiol levels of $25.5 \pm 5.6 \mathrm{pg} / \mathrm{ml}$. Nonpregnant females thus had slightly higher levels of estradiol than untreated ovariectomized females. Since the estradiol levels of untreated females were all below the level of assay detectability, an analysis of the difference in estradiol between nonpregnant females and untreated females was not conducted. Nonpregnant females had progesterone levels comparable to both treated and untreated ovariectomized females (Table 1).

Nonpregnant females did not differ from untreated ovariectomized females on any measure of femaleinitiated behavior (Table 2, Fig. 1). In contrast, nonpregnant females differed significantly from estradioltreated ovariectomized females in all female-initiated behaviors except for proximity and contact durations (Table 2, Fig. 1). Male-initiated behavior toward females was not different in either the comparison of nonpregnant females with untreated ovariectomized

TABLE 2

Comparisons of Female-Initiated Behaviors in Different Groups

\begin{tabular}{|c|c|c|c|c|c|c|}
\hline Behavior & $\begin{array}{c}\text { Ovex with E } \\
(\text { Mean } \pm \text { SEM) }\end{array}$ & $\begin{array}{l}\text { Ovex without } E \\
(\text { Mean } \pm \text { SEM) }\end{array}$ & $\begin{array}{c}\text { Nonpregnant } \\
\text { females } \\
\text { (Mean } \pm \text { SEM) }\end{array}$ & $\begin{array}{c}\text { Ovex E vs } \\
\text { Ovex No E } \\
F(1,4) ; P\end{array}$ & $\begin{array}{c}\text { Ovex E vs } \\
\text { Nonpregnant } \\
t(\mathrm{df}) ; P\end{array}$ & $\begin{array}{c}\text { Ovex No E vs } \\
\text { Nonpregnant } \\
t(\mathrm{df}) ; P\end{array}$ \\
\hline Approach frequency & $15.0 \pm 3.8$ & $1.0 \pm 0.5$ & $2.2 \pm 1.2$ & $14.31 ; 0.05$ & $3.21(8.0) ; 0.01$ & $0.87(8.0) ; \mathrm{ns}$ \\
\hline Proximity duration & $17.5 \pm 7.7$ & $0.8 \pm 0.4$ & $1.2 \pm 0.9$ & $4.61 ; 0.10$ & $2.09(4.1) ; 0.10$ & $1.12(4.4) ; \mathrm{ns}$ \\
\hline Contact frequency & $7.0 \pm 1.3$ & $1.4 \pm 0.6$ & $1.0 \pm 0.8$ & $29.58 ; 0.01$ & $3.87(8.0) ; 0.01$ & $1.11(8.0) ; \mathrm{ns}$ \\
\hline Contact duration & $9.1 \pm 3.2$ & $1.1 \pm 0.9$ & $1.3 \pm 1.1$ & & $2.32(5.0) ; 0.10$ & $1.10(4.0) ; \mathrm{ns}$ \\
\hline Corrected means & $8.2 \pm 1.2$ & $2.0 \pm 1.8$ & & $15.56 ; 0.05$ & & \\
\hline Groom frequency & $6.4 \pm 1.8$ & $1.6 \pm 0.8$ & $1.0 \pm 0.8$ & $9.85 ; 0.05$ & $2.75(5.4) ; 0.05$ & $1.18(8.0) ; \mathrm{ns}$ \\
\hline Groom duration & $18.8 \pm 6.5$ & $7.9 \pm 4.0$ & $0.5 \pm 0.3$ & $1.30 ; \mathrm{ns}$ & $2.81(4.0) ; 0.05$ & 1.82 (4.1); ns \\
\hline Present frequency & $4.4 \pm 1.4$ & $0.0 \pm 0.0$ & $0.0 \pm 0.0$ & $9.88 ; 0.05$ & $3.14(4.0) ; 0.05$ & \\
\hline
\end{tabular}

Note. Frequency measures are reported in number per $6 \mathrm{~h}$ of observation. Duration measures are reported in minutes per $6 \mathrm{~h}$ of observation. 
A

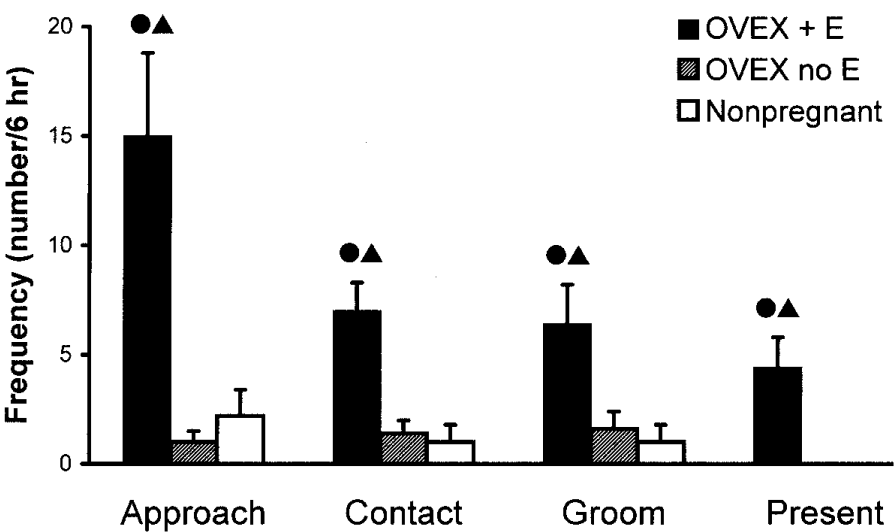

B

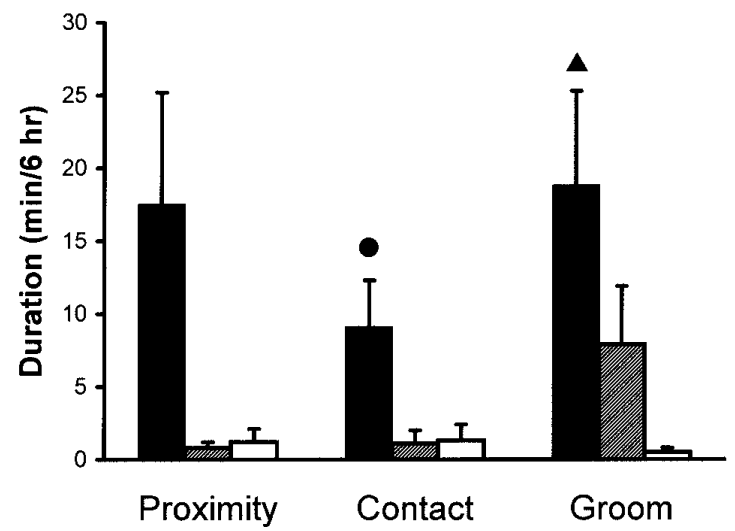

FIG. 1. Effects of estradiol on the (a) frequency and (b) duration of female-initiated behaviors. Estradiol-treated females had significantly higher frequencies of approaches, contacts, grooming bouts, and presents toward males than untreated females and nonpregnant females. Estradiol-treated females spent more time in contact with males than untreated females and spent more time grooming males than did nonpregnant females. There were no differences between untreated and nonpregnant females in any of these behaviors. Symbols represent a significant difference in means $(P \leq 0.05)$ in ovariectomized females during estradiol treatment and oil treatment $(\boldsymbol{\bullet})$ or between estradioltreated ovariectomized females and nonpregnant females $(\mathbf{\Lambda})$.

females or the comparison of nonpregnant females with estradiol-treated females (Table 3).

\section{Correlations between Hormones and Behavior}

Both estradiol and progesterone accounted for a large portion of the variance in female-initiated behaviors (Table 4). Estradiol levels alone accounted for a significant amount of the variance in contact frequency, grooming frequency, and grooming duration. The addition of progesterone in a stepwise regression analysis significantly increased the amount of variance accounted for in each of these behaviors. Although neither estradiol nor progesterone individually correlated significantly with female-initiated contact duration, the two hormones combined accounted for a significant amount of variance in this behavior when entered into a stepwise regression of estradiol followed by progesterone. Female presentations were influenced by estradiol only. Female-initiated approaches to proximity and proximity durations were not correlated with either of these two hormones.

Although all male-initiated behaviors occurred infrequently (Table 3), male-initiated contact behavior was also related to the hormonal profiles of females (Table 4). In contrast to female-initiated behaviors,

TABLE 3

Comparisons of Male-Initiated Behaviors in Different Groups

\begin{tabular}{|c|c|c|c|c|c|c|}
\hline Behavior & $\begin{array}{c}\text { Ovex with E } \\
(\text { Mean } \pm \text { SEM) }\end{array}$ & $\begin{array}{l}\text { Ovex without } \mathrm{E} \\
(\text { Mean } \pm \text { SEM) }\end{array}$ & $\begin{array}{c}\text { Nonpregnant } \\
\text { females } \\
\text { (Mean } \pm \text { SEM) }\end{array}$ & $\begin{array}{l}\text { Ovex E vs } \\
\text { Ovex No E } \\
F(1,4) ; P\end{array}$ & $\begin{array}{c}\text { Ovex E vs } \\
\text { Nonpregnant } \\
t(\mathrm{df}) ; P\end{array}$ & $\begin{array}{c}\text { Ovex No E vs } \\
\text { Nonpregnant } \\
t(\mathrm{df}) ; P\end{array}$ \\
\hline Approach frequency & $1.8 \pm 0.6$ & $2.0 \pm 0.8$ & $3.8 \pm 0.8$ & $\leq 1.0 ; \mathrm{ns}$ & $0.20(8.0) ; \mathrm{ns}$ & 1.50 (8.0); ns \\
\hline Proximity duration & $1.6 \pm 1.0$ & $2.1 \pm 1.1$ & $2.9 \pm 1.1$ & $\leq 1.0 ; \mathrm{ns}$ & $0.35(8.0) ; \mathrm{ns}$ & 0.50 (8.0); ns \\
\hline Contact frequency & $1.2 \pm 0.6$ & $0.6 \pm 0.4$ & $0.2 \pm 0.2$ & & 1.62 (4.9); ns & 0.89 (8.0); ns \\
\hline Corrected means & $1.1 \pm 0.3$ & $0.7 \pm 0.4$ & & $\leq 1.0 ; \mathrm{ns}$ & & \\
\hline Contact duration & $0.3 \pm 0.1$ & $0.2 \pm 0.2$ & $0.0 \pm 0.0$ & $\leq 1.0 ; \mathrm{ns}$ & 1.89 (4.8); ns & 1.26 (4.1); ns \\
\hline Groom frequency & $1.2 \pm 1.0$ & $0.6 \pm 0.2$ & $0.2 \pm 0.2$ & $\leq 1.0 ; \mathrm{ns}$ & $1.01(8.0) ; \mathrm{ns}$ & 1.27 (8.0); ns \\
\hline Groom duration & $4.1 \pm 3.6$ & $1.9 \pm 1.3$ & $0.3 \pm 0.4$ & $\leq 1.0 ; \mathrm{ns}$ & 1.03 (4.1); ns & 1.22 (4.4); ns \\
\hline Mount frequency & $0.6 \pm 0.4$ & $0.0 \pm 0.0$ & $0.0 \pm 0.0$ & $\leq 1.0 ; \mathrm{ns}$ & 1.50 (4.0); ns & \\
\hline Aggression frequency & $0.8 \pm 0.2$ & $0.4 \pm 0.4$ & $0.6 \pm 0.3$ & $\leq 1.0 ; \mathrm{ns}$ & $0.45(8.0) ; \mathrm{ns}$ & 0.45 (8.0); ns \\
\hline
\end{tabular}

Note. Frequency measures are reported in number per $6 \mathrm{~h}$ of observation. Duration measures are reported in minutes per $6 \mathrm{~h}$ of observation. 


\section{TABLE 4}

Significant Relationships between Hormone Levels and Behavior

\begin{tabular}{|c|c|c|c|c|c|c|c|c|c|c|c|}
\hline \multicolumn{2}{|c|}{ Behavioral interaction } & \multicolumn{3}{|c|}{ Estrogen } & \multicolumn{3}{|c|}{ Progesterone } & \multicolumn{4}{|c|}{ Stepwise regression } \\
\hline Behavior & Initiated by & $r$ & $r^{2}$ & $P$ & $r$ & $r^{2}$ & $P$ & Order & $r$ & $r^{2}$ & $P$ \\
\hline Contact frequency & Female & 0.88 & 0.77 & 0.001 & 0.31 & 0.10 & ns & $\mathrm{E}, \mathrm{P}$ & 0.95 & 0.89 & 0.001 \\
\hline Contact duration & Female & 0.50 & 0.25 & ns & -0.48 & 0.23 & ns & $\mathrm{E}, \mathrm{P}$ & 0.77 & 0.59 & 0.05 \\
\hline Groom frequency & Female & 0.74 & 0.54 & 0.05 & -0.32 & 0.10 & ns & $\mathrm{E}, \mathrm{P}$ & 0.87 & 0.76 & 0.01 \\
\hline Groom duration & Female & 0.64 & 0.41 & 0.05 & -0.41 & 0.17 & ns & $\mathrm{E}, \mathrm{P}$ & 0.84 & 0.70 & 0.01 \\
\hline Present frequency & Female & 0.81 & 0.65 & 0.005 & 0.24 & 0.06 & ns & E only & & & \\
\hline Contact frequency & Male & 0.32 & 0.10 & ns & -0.73 & 0.53 & 0.05 & $\mathrm{P}, \mathrm{E}$ & 0.86 & 0.74 & 0.01 \\
\hline Contact duration & Male & 0.36 & 0.13 & ns & -0.64 & 0.41 & 0.05 & $\mathrm{P}, \mathrm{E}$ & 0.81 & 0.65 & 0.05 \\
\hline
\end{tabular}

Note. A second hormone was added into the stepwise regression only if there was a significant increase in the amount of variance explained by the regression. Averaged data from estrogen treated ovariectomized females and from nonpregnant females are included in this analysis.

progesterone levels rather than estradiol levels accounted for more of the variance and were negatively correlated with frequency and duration of male-initiated contact. The addition of estradiol in a stepwise regression analysis significantly increased the amount of variance accounted for in these two behaviors. All other male-initiated behaviors were not related to the hormonal levels of estradiol or progesterone in the females.

\section{DISCUSSION}

Estradiol treatment induced increased sexual initiation by ovariectomized female rhesus monkeys in the absence of similar changes in male sexual activity and while levels of male-initiated interactions were extremely low. Estradiol-treated ovariectomized females also displayed greater sexual initiation than intact, noncycling, nonpregnant females. These results provide clear evidence that estrogen influences female sexual interest, independent of the level of male sexual interest or activity. These results parallel those from pair-tests that increased female control of the sexual interaction (Bonsall, Zumpe, and Michael, 1978; Czaja and Bielert, 1975; Pomerantz and Goy, 1983). Under our testing conditions, variation in several measures of female sexual initiation were best accounted for by both estradiol and progesterone levels. This finding supports previous correlational findings in intact, cycling female rhesus monkeys (Wallen et al., 1984). Interestingly, even though the present study did not manipulate progesterone levels, endogenous variation in progesterone was significantly negatively correlated with the occurrence of female sexual initiation. This finding extends our understanding of the impor- tant role progesterone probably plays in inhibiting female rhesus monkey sexual behavior (Baum, Keverne, Everitt, Herbert, and de Greef, 1977), either during the luteal phase of intact cycles (Wallen et al., 1984) or during the early postconception period (Wilson, Gordon, and Collins, 1982a). Taken together, these results suggest that estrogen and progesterone are modulators of female rhesus monkey sexual motivation and that the effects of these hormones counter each other.

In contrast to female-initiated behavior, male-initiated behavior occurred infrequently and did not show increases associated with estradiol treatment of the females, a finding consistent with the nonbreeding season behavior of male rhesus monkeys. Although behavior was limited, the male contact behavior that did occur was correlated with female hormonal condition. Interestingly, female progesterone levels, rather than estradiol levels, explained the largest amount of variance in male-initiated contact behavior. Progesterone was negatively correlated with contact behavior; this finding is consistent with the view that progesterone decreases female attractiveness, thus reducing male sexual initiation (Baum et al., 1977a). Our finding that low endogenous levels of progesterone in rhesus monkeys produced similar effects suggests a broader role for progesterone in modulating rhesus monkey sexual behavior than previously thought.

This study provides further support for distinguishing sexual motivation from sexual behavior (Wallen, 1990). Sexual behavior is an interaction between a male and a female and thus reflects the motivational state of both. Since, in primates, copulation can physically occur at any time in the menstrual cycle (Miller, 1931; Wallen, 1995), hormonal changes during the cycle neither determine nor, under some testing condi- 
tions, predict the frequency of sexual behavior (Johnson and Phoenix, 1978). In contrast, changes in the female's willingness to mate, as indicated by her sexual initiation with males, correlate strongly with hormonal changes during the menstrual cycle when females are observed in multifemale social groups (Gordon, 1981; Wilson, Gordon, and Collins, 1982b; Wallen et al., 1984). However, such changes in female sexual initiation are not always associated with changes in copulation. This tight coupling between ovarian hormone changes and variation in female sexual motivation may reflect an adaptation for dealing with social constraints on female behavior imposed by multifemale groups (Wallen, 1995). In such groups, female-female agonism and aggression increase during the periovulatory portion of the ovarian cycle when females also increase their interactions with males (Walker, Wilson, and Gordon, 1983; Wallen and Tannenbaum, 1997). Without a system of hormonally modulated female sexual motivation, such negative social interactions between females could suppress or eliminate mating.

Ours is not the first study to report increases in female sexual motivation as result of estradiol treatment during the nonbreeding season, although it is the first to show increases in male-female interactions. Pope, Wilson, and Gordon (1987) reported that estradiol treatment during the nonbreeding season increased female-female sexual behavior without increasing male-directed behavior. In contrast, we found increased male-directed behavior without increased same-sex sexual behavior. While both studies provide evidence that estrogen influences sexual motivation in female rhesus monkeys, it is difficult to explain the different behavioral expression taken in the two studies, particularly since both studies used the same ovariectomized females. One possibility is that the results of the earlier study were influenced by the younger age of the females. These females had been ovariectomized prepubertally and had limited sexual experience with males when they received estradiol treatment during the nonbreeding season in the previous study. When these same females were exposed to estradiol in the current study, they had received multiple estradiol treatments during the intervening 12 years and all had been sexually active with group males during previous hormonal treatments (Wallen, personal observation). The contrasting findings of these two studies may also reflect methodological differences. The current study focused specifically on measures of female sexual initiation during a $60-\mathrm{min}$ observation period whereas the previous study used a methodology that would not capture these patterns of behavior in similar detail. Whatever the explanation for these differing results, both studies support the notion that estrogen modulates sexual motivation in rhesus monkeys and suggest that the specific behavioral expression of sexual motivation depends upon specific social circumstances and history.

The results of this study contradict the view that androgens, of adrenal origin, influence sexual motivation (Everitt and Herbert, 1969; Everitt, Herbert, and Hamer, 1972; Baum, Everitt, Herbert, and Keverne, 1977). The females in the present study, when untreated with estradiol, would have had normal adrenal androgen levels, yet they displayed little or no sexual interest in the males. In contrast, when treated with estradiol they displayed marked and consistent increases in sexual initiation. We have previously demonstrated that suppression of adrenal function in group-living rhesus monkey females does not decrease female sexual initiation (Lovejoy and Wallen, 1990). In contrast, suppression of ovarian function, with intact adrenal function, eliminates female sexual initiation (Wallen, Mann, Davis-DaSilva, Gaventa, Lovejoy, and Collins, 1986) and changes in female sexual initiation are strongly correlated with changes in circulating estradiol, but not androgen (Wallen et al., 1984). Thus, the converging evidence strongly supports the notion that estrogen, not androgen, is the primary regulator of sexual motivation in female rhesus monkeys.

Estrogen appears to modulate sexual motivation in other nonhuman primate species as well. Copulatory behavior varies with the ovarian cycle in primate species ranging from New World monkeys to apes (for review see Dixson, 1990). For example, ovariectomized common marmoset females show increased female-initiated sexual behavior in response to estrogen, decreased behavior in response to progesterone, and unchanged behavior in response to testosterone administration (Kendrick and Dixson, 1985). Proceptive behaviors can be eliminated with excitotoxic lesions of the hypothalamus, indicating that circulating hormonal levels may modulate female sexual behavior through this brain region (Dixson, 1990; Dixson and Hastings, 1992). Finally, removal of adrenal androgens does not affect female initiation of sexual behavior in common marmosets (Dixson, 1987).

Human female sexual interest decreases following ovariectomy (Sherwin and Gelfland, 1987). It has been suggested that androgens modulate human female sexual interest (Waxenberg, Drellich, and Sutherland, 1959; Sherwin, Gelfland, and Brender, 1985; Sherwin 
and Gelfland, 1987). Although several studies show increased sexual desire during combined estrogen and androgen treatment (Sherwin et al., 1985; Sherwin and Gelfland, 1987), in least one study, ovariectomized women with androgen levels three to four times the peak physiological level report little or no sexual desire until receiving estrogen therapy in addition to elevated androgens (Sherwin and Gelfland, 1987). Thus evidence from a wide variety of nonhuman primate females and women suggests that estrogen increases female sexual motivation.

\section{ACKNOWLEDGMENTS}

This study was supported in part by an NSF Graduate Fellowship to J.L.Z., by NIH Grant R03-MH56328 and an H. F. Guggenheim Foundation grant to D.M., by NIH Grants R01-MH50268 and K02-MH01062 to K.W., and by NIH Grant RR-00165 to the Yerkes Regional Primate Research Center. We thank Katherine Paul for performing the surgeries, Lindsey Stillman for help in data collection, and Ari Measday, Ben Jones, and Andrew Kennedy for assistance with animal handling procedures. All hormonal assays were performed by Yerkes Assay Services. The Yerkes Center is fully accredited by the American Association for Accreditation of Laboratory Animal Care.

\section{REFERENCES}

Altmann, S. A. (1962). A field study of the sociobiology of rhesus monkeys, Macaca mulatta. Ann. N.Y. Acad. Sci. 102, 338-435.

Baum, M. J., Keverne, E. B., Everitt, B. J., Herbert, J., and de Greef, W. J. (1977a). Effects of progesterone and estradiol on sexual attractivity of female rhesus monkeys. Physiol. Behav. 18, 659-670.

Baum, M. J., Everitt, B. J., Herbert, J., and Keverne, E. B. (1977b). Hormonal basis of proceptivity and receptivity in female primates. Arch. Sex. Behav. 6, 173-192.

Bonsall, R. W., Zumpe, D., and Michael, R. P. (1978). Menstrual cycle influences on operant behavior of female rhesus monkeys. J. Comp. Physiol. Psychol. 92, 846-855.

Czaja, J. A., and Bielert, C. (1975). Female rhesus sexual behavior and distance to a male partner: Relation to stage of the menstrual cycle. Arch. Sex. Behav. 4, 583-597.

Czaja, J. A., Robinson, J. A., Eisele, S. G., Scheffler, G., and Goy, R. W. (1977). Relationship between sexual skin colour of female rhesus monkeys and the midcycle plasma levels of oestradiol and progesterone. J. Reprod. Fertil. 49, 147-150.

Dixson, A. F. (1990). The neuroendocrine regulation of sexual behaviour in female primates. Ann. Rev. Sex Res. 1, 197-226.

Dixson, A. F., and Hastings, M. H. (1992). Effects of ibotenic acidinduced neuronal degeneration in the hypothalamus upon proceptivity and sexual receptivity in the female marmoset (Callithrix jacchus). J. Neuroendocrinol. 4, 719-726.

Everitt, B. J., and Herbert J. (1969). Adrenal glands and sexual receptivity in female rhesus monkeys. Nature 222, 1065-1066.

Everitt, B. J., Herbert, J., and Hamer, J. D. (1972). Sexual receptivity of bilaterally adrenalectomized female rhesus monkeys. Physiol. Behav. 8, 409-415.

Goldfoot, D. A. (1981). Olfaction, sexual behavior, and the pheromone hypothesis in rhesus monkeys: A critique. Am. Zool. 21, 153-164.

Gordon, T. P. (1981). Reproductive behavior in the rhesus monkey: Social and endocrine variables. Am. Zool. 21, 185-195.

Gordon, T. P., Bernstein, I. S., and Rose, R. M. (1978). Social and seasonal influences on testosterone secretion in the male rhesus monkey. Physiol. Behav. 21, 623-627.

Goy, R. W. (1979). Sexual compatibility in rhesus monkeys: Predicting sexual behavior of oppositely sexed pairs of animals. In Ciba Foundation Symposium, Sex, Hormones, and Behavior, pp. 227-255. Elsevier-North Holland, Amsterdam.

Herndon, J. G., Turner, J. J., Ruiz de Elvira, M. C., and Collins, D. C. (1987). Silent ovulation in rhesus monkeys (M. mulatta): Dissociation of hormonal and behavioral states. Physiol. Behav. 40, 665672.

Johnson, D. F., and Phoenix, C. H. (1978). Sexual behavior and hormone levels during the menstrual cycle of rhesus monkeys. Horm. Behav. 11, 160-174.

Kendrick, K. M., and Dixson, A. F. (1985). Effects of oestradiol 17B, progesterone and testosterone upon proceptivity and receptivity in ovariectomized common marmosets (Callithrix jacchus). Physiol. Behav. 34, 123-128.

Keppel, G. (1991). Design and Analysis: A Researcher's Handbook, 3rd ed. Prentice Hall, Englewood Cliffs, NJ.

Lovejoy, J., and Wallen, K. (1990). Adrenal suppression and sexual initiation in group-living female rhesus monkeys. Horm. Behav. 24, 256-269.

Michael, R. P., and Bonsall, R. W. (1979). Hormones and the sexual behavior of rhesus monkeys. In C. Beyer (Ed.), Endocrine Control of Sexual Behavior, pp. 279-301. Raven Press, New York.

Miller, G. S. (1931). The primate basis for human sexual behavior. $Q$. Rev. Biol. 6, 379-410.

Pomerantz, S. M., and Goy, R. W. (1983). Proceptive behavior of female rhesus monkeys during tests with tethered males. Horm. Behav. 17, 237-248.

Pope, N. S., Wilson, M. E., and Gordon, T. P. (1987). The effect of season on the induction of sexual behavior by estradiol in female rhesus monkeys. Biol. Reprod. 36, 1047-1054.

Sherwin, B. B., and Gelfland, M. M. (1987). The role of androgens in the maintenance of sexual functioning in oophorectomized women. Psychosom. Med. 49, 397-409.

Sherwin, B. B., Gelfland, M. M., and Brender, W. (1985). Androgen enhances sexual motivation in females: A prospective, crossover study of sex steroid administration in surgical menopause. Psychosom. Med. 47, 339-351.

Van Horn, R. N. (1980). Seasonal reproductive patterns in primates. Prog. Reprod. Biol. 5, 181-221.

Walker, M. L., Wilson, M. E., and Gordon, T. P. (1983). Female rhesus monkey aggression during the menstrual cycle. Anim. Behav. 31, 1047-1054.

Walker, M. L., Wilson, M. E., and Gordon, T. P. (1984). Endocrine control of seasonal occurrence of ovulation in rhesus monkeys housed outdoors. Endocrinology 114, 1074-1081.

Wallen, K. (1990). Desire and ability: Hormones and the regulation of female sexual behavior. Neurosci. Biobehav. Rev. 14, 233-241.

Wallen, K. (1995). The evolution of female sexual desire. In P. R. Abramson and S. D. Pinkerton (Eds.), Sexual Nature Sexual Culture, pp. 57-79. Univ. of Chicago Press, Chicago.

Wallen, K., Mann, D. R., Davis-DaSilva, M., Gaventa, S., Lovejoy, 
J. C., and Collins, D. C. (1986). Chronic gonadotropin-releasing hormone agonist treatment suppresses ovulation and sexual behavior in group-living female rhesus monkeys. Physiol. Behav. 36, 369-375.

Wallen, K., and Tannenbaum, P. L. (1997). Hormonal modulation of sexual behavior and affiliation in rhesus monkeys. Ann. N.Y. Acad. Sci. 807, 185-202.

Wallen, K., and Winston, L. A. (1984). Social complexity and hormonal influences on sexual behavior in rhesus monkeys (Macaca mulatta). Physiol. Behav. 32, 629-637.

Wallen, K., Winston, L. A., Gaventa, S., Davis-DaSilva, M., and Collins, D. C. (1984). Periovulatory changes in female sexual behavior and patterns of ovarian steroid secretion in group-living rhesus monkeys. Horm. Behav. 18, 431-450.

Waxenberg, S. E., Drellich, M. G., and Sutherland, A. M. (1959). The role of hormones in human behavior. I. Changes in female sexuality after adrenalectomy. J. Clin. Endocrinol. 19, 193-202.

Wilson, M. E., Gordon, T. P., and Collins, D. C. (1982a). Serum $17 \beta$-estradiol and progesterone associated with mating behavior during early pregnancy in female rhesus monkeys. Horm. Behav. 16, 94-106.

Wilson, M. E., Gordon, T. P., and Collins, D. C. (1982b). Variation in ovarian steroids associated with the annual mating period in female rhesus (Macaca mulatta). Biol. Reprod. 27, 530-539. 